\title{
Aprendizado Baseado em Projetos em IHC (presencial e remoto): prototipação segundo as heurísticas de Nielsen
}

\author{
Luciana Mara Freitas Diniz ${ }^{1}$, Marcus Vinícius Pereira ${ }^{1}$, \\ Lucas Júnior Dias de Paula ${ }^{1}$, Eduardo César de Melo Silva ${ }^{1}$ \\ ${ }^{1}$ Faculdade de Pará de Minas - FAPAM - Pará de Minas, MG - Brasil \\ \{lucianamfd, pereiramarcus93, lucasmg37@gmail.com, educ.ms@outlook.com.br\}
}

\begin{abstract}
Resumo. A aprendizagem de novos conteúdos vai além de assistir aulas e realizar exercícios conceituais e, por vezes, se faz necessária a realização de trabalhos práticos. A metodologia de aprendizado baseado em projetos apresenta o aluno como protagonista neste processo de captação e internalização do conhecimento, uma vez que pratica a teoria estudada. Este relato de experiências descreve a aplicação da metodologia supracitada por meio da elaboração de protótipos interativos de alta fidelidade, baseados nas heurísticas de usabilidade de Nielsen. O projeto ocorreu em uma disciplina de Interação HumanoComputador, nas modalidades de ensino presencial e remoto.
\end{abstract}

\section{Introdução}

A disciplina de Interação Humano-Computador (IHC) é ofertada aos alunos do $5^{\circ}$ período do curso tecnológico em Gestão da TI da Faculdade de Pará de Minas (FAPAM), situada na cidade homônima, localizada no interior de Minas Gerais. Sua ementa contempla conteúdos relacionados aos aspectos humanos e computacionais, com foco na usabilidade, por meio da coleta das necessidades dos usuários, design e avaliação de interfaces.

É sabido que a IHC e a Engenharia de Software (ES) possuem diferentes perspectivas sobre o desenvolvimento de sistemas interativos, porém há um caminho para integração entre ambas, uma vez que a qualidade de uso é preocupação compartilhada em processos das duas disciplinas [Barbosa 2010]. Dado que a disciplina de Engenharia de Software I é ofertada no mesmo período e ministrada pela mesma professora, surgiu a ideia de propor um projeto interdisciplinar, cuja abordagem se daria de forma integrada, uma vez que as duas disciplinas comungam aspectos complementares, como demonstram alguns autores [Barbosa 2010, de Lima et al. 2019]. A interdisciplinaridade é um componente curricular importante em cursos de graduação, entretanto, o foco deste artigo se restringe apenas às partes do projeto relacionadas à disciplina de IHC.

O objetivo principal do projeto foi simular a integração de ambas as disciplinas, assim como ocorre nas empresas e no mercado de trabalho como um todo e, além disso, proporcionar aos alunos esta percepção. Os relatos são compartilhados sob o ponto de vista da professora, que possui graduação em Ciência da Computação, mestrado em Ciência da Informação e, desde 2013, leciona a disciplina de IHC na referida instituição. Sua experiência como docente no ensino superior se estende há mais de 9 anos.

$\mathrm{O}$ artigo apresenta detalhes de duas ofertas da disciplina ( $1^{\circ}$ semestre de 2019 e $1^{\circ}$ semestre de 2020), embasada na mesma especificação de projeto, porém em modalidades de ensino distintas: presencial e remoto, sendo esta última, adotada temporariamente 
pela faculdade, devido à pandemia do novo coronavírus. A metodologia se pautou na aprendizagem baseada em projetos, que estimula o desenvolvimento de competências, o protagonismo dos alunos e o trabalho em equipe na aplicação prática de conteúdos disciplinares [Chagas 2020]. Para isso, foi proposta a construção de um protótipo funcional de alta fidelidade para sistemas interativos, com tema de livre escolha dos alunos e com liberdade e autonomia para explorar e aplicar suas ideias e/ou mesmo propor soluções para problemas reais. Os protótipos deveriam apresentar em suas interfaces gráficas a presença de algumas heurísticas descritas por [Nielsen 1993].

Mais detalhes encontram-se dispostos no referencial teórico, com conteúdos norteadores sobre Interação Humano-Computador e Aprendizagem Baseada em Projetos. Na sequência, é detalhado o desenvolvimento do projeto na disciplina de IHC e, por fim, há a apresentação dos resultados e as considerações finais.

\section{Referencial Teórico}

\subsection{IHC e conceitos relacionados}

De acordo com [Barbosa 2010], a área de Interação Humano-Computador tem interesse na qualidade de uso de sistemas interativos e em como isto afeta seus usuários. Para que o impacto seja positivo, os elementos presentes na interface destes sistemas devem ser projetados de acordo com o proposto pelo design de interação, que aborda a intuitividade, a clareza das funcionalidades e as possibilidades presentes nas aplicações [Sobral 2019].

Um sistema planejado seguindo as instruções de design, tende a ser dotado de usabilidade, o que significa dizer que o usuário será capaz de realizar tarefas de maneira eficiente, agradável e eficaz em um contexto de uso específico [ISO 9241-11 2018]. Segundo [Benyon 2011], o design de interface "consiste em tudo o que há no sistema que as pessoas entram em contato seja física, perceptiva ou conceitualmente", e que resultará na melhor experiência do usuário ao utilizar determinado sistema.

É por meio dos protótipos que os designers apresentam aspectos visuais do design de interface, pois devem ser usados para validar propostas de solução junto aos usuários de um sistema e podem aparecer com níveis de detalhamentos distintos. Os protótipos de alta fidelidade $(\mathrm{Hi}$-fi) possuem grande similaridade com o produto final, sendo até confundidos com uma aplicação real, uma vez que há o intuito de simular os recursos funcionais do sistema [Sobral 2019]. Nestes casos, a utilização de ferramentas computacionais se faz necessária para a construção das interfaces.

A presença de características desejáveis nas interfaces reforçam a busca pela qualidade em sistemas interativos [Barbosa 2010], o que remete ao conjunto de diretrizes de usabilidade de Nielsen. As heurísticas [Nielsen 1993], como são conhecidas, fazem parte de uma avaliação de IHC na busca por problemas que desfavorecem a usabilidade, no qual as interfaces são inspecionadas por avaliadores. O conjunto das 10 heurísticas foi suprimido neste relato, uma vez que é bastante conhecido na comunidade de pesquisadores e atuantes da área de IHC.

\subsection{Project Based Learning}

A metodologia de Aprendizagem Baseada em Projetos, tradução de Project Based Learning (PBL), permite que os alunos aprendam fazendo e aplicando ideias, uma vez 
que há envolvimento com problemas reais [Krajcik and Blumenfeld 2005]. Conforme [Chagas 2020], é importante identificar um conteúdo da disciplina que possa ser explorado e desenvolvido com os alunos na forma de um projeto. Segundo a mesma autora, cada uma das entregas são denominadas de produto, seja um relatório, um diagnóstico, um aplicativo ou um protótipo, como é o caso deste relato.

De acordo com [Mesquita et al. 2018], tal abordagem caracteriza-se pelos princípios de interdisciplinaridade, trabalho em equipe e identificação de um problema. Para os autores, o elemento norteador do PBL é o problema, o qual confere à aprendizagem aspectos de relevância e significado, além de promover processos criativos e inovadores ao desenvolver o projeto. A interdisciplinaridade se apresenta como o elemento diferenciador do PBL, pois promove a integração da teoria com a prática e, ainda, os alunos estarão aptos a interligar diferentes áreas do conhecimento ou áreas complementares. Por fim, o trabalho em equipe proporciona aos alunos atuarem de forma colaborativa.

\section{PBL na disciplina de IHC}

A disciplina de IHC, com carga horária de 40 horas semestrais, é ofertada anualmente e ocorre nos semestres ímpares, com um encontro semanal de 2 horas/aula. Mediante o que propõem as ciências da aprendizagem e as suas quatro ideias principais destacadas pelos autores [Krajcik and Blumenfeld 2005], a metodologia de aprendizagem baseada em projetos se adequou à proposta inicial da professora. A seguir, cada uma delas é apresentada de forma contextualizada conforme sua aplicação na disciplina:

a) construção ativa: construção do protótipo interativo de alta fidelidade, com a restrição de conter no mínimo 5 telas para sistemas ou aplicativos. $O$ tema foi livre e cada equipe teve autonomia para explorar e aplicar suas ideias ou mesmo propor soluções para problemas reais. Além disso, o protótipo deveria ser funcional, de modo que houvesse a possibilidade de navegar entre as interfaces criadas, por meio de links nos botões.

b) aprendizagem situada: inclusão de, no mínimo, 4 heurísticas de Nielsen [Nielsen 1993], para elaboração dos protótipos, aliando a teoria das aulas à prática de um projeto real. $\mathrm{O}$ design das interfaces deveria ser pautado e justificado com base nas heurísticas utilizadas. Ao invés de usar as heurísticas na avaliação as interfaces gráficas, como comumente acontece, elas foram usadas em sua elaboração.

c) interações sociais: ao todo, 20 alunos participaram dos projetos - 9 alunos em 2019 e 11 alunos em 2020. Cada equipe teve de 3 a 4 integrantes. A realização do projeto individualmente não foi permitida, pois o trabalho conjunto seria objeto da abordagem PBL. Além disso, o conhecimento compartilhado promove o desenvolvimento de soft skills ${ }^{1}$, bastantes requeridas pelo mercado de trabalho atual e, principalmente, na área de tecnologia da informação, na qual equipes são compostas por profissionais de múltiplas áreas.

d) ferramentas cognitivas: a escolha de qual ferramenta de prototipação utilizar foi de livre escolha dos alunos, levando em consideração as habilidades e conhecimentos que porventura já tivessem, como foi o caso da ferramenta Adobe XD, de domínio de alguns alunos no $1^{\circ}$ semestre de 2019. No entanto, dois horários de 50 minutos cada, em ambos os semestres, foram dedicados ao ensino de uma determinada ferramenta. As aulas foram conduzidas de modo a explorar os recursos disponíveis em cada uma delas, como manipulação e edição de elementos, botões, cores, exportação de imagens e criação de

\footnotetext{
${ }^{1}$ Habilidades e competências nas relações humanas: empatia, colaboração, comunicação.
} 
links entre as telas prototipadas. No $1^{\circ}$ semestre de 2019, a ferramenta Pencil Project ${ }^{2}$ foi adotada, uma vez que estava pré-instalada no laboratório de práticas computacionais da faculdade, onde os alunos tiveram mais duas aulas dedicadas à elaboração dos protótipos, com a supervisão da professora. Já no $1^{\circ}$ semestre de 2020, o Figma ${ }^{3}$ foi a ferramenta escolhida, haja visto que as aulas aconteciam remotamente, de forma síncrona, por meio da plataforma de videochamadas Google Meet. Outro aspecto importante pela escolha de tal ferramenta é que ela permite a construção colaborativa de até duas pessoas com acesso via e-mail (uma vantagem para os alunos trabalharem de forma conjunta). $\mathrm{Na}$ aula sobre o Figma, a professora utilizou os recursos de compartilhamento de tela e de gravação do Google Meet. O arquivo com a aula gravada foi disponibilizado aos alunos posteriormente para reverem quantas vezes fossem necessárias. No ensino remoto, a supervisão se deu em horários e meios alternativos: por aplicativo de mensagens, e-mail e após o término das aulas semanais da disciplina, via videoconferência. Em ambas as modalidades de ensino, foi possível sanar as principais dúvidas dos alunos.

\subsection{Interdisciplinaridade entre IHC e ES1}

O projeto iniciou no início de março (em ambos os semestres), com uma primeira entrega em meados do mês de abril, contendo uma documentação com os requisitos, as regras de negócio, o diagrama e a descrição dos casos de uso da aplicação a ser modelada - itens específicos da disciplina de ES1. No início de maio, após as correções feitas pela docente, os documentos foram devolvidos aos alunos para que fizessem as alterações necessárias e a inclusão de itens referentes à uma segunda entrega, que contemplou o diagrama e a descrição das classes, além da modularização dos componentes do sistema e, ainda, a prototipação das interfaces gráficas, conforme já descrito. Os requisitos funcionais entregues na primeira parte, foram o ponto de partida para a construção dos protótipos. A apresentação dos projetos ocorreu no final de junho.

\section{Resultados dos projetos}

Dentre todas as prototipações, quatro foram representações de sistemas web e duas de aplicativos mobile. No $1^{\circ}$ semestre de 2019, 2 grupos usaram a ferramenta Pencil Project e 1 grupo a ferramenta Adobe XD, sendo esta última, mesmo não tendo sido abordada na disciplina, foi escolhida porque membros do grupo já tinham contato com as ferramentas da suíte Adobe e optaram por ela. Já em 2020, todos os grupos criaram os protótipos utilizando a ferramenta Figma.

Tendo em vista a quantidade significativa de protótipos e a limitação de espaço para apresentação de todos eles, foi escolhido o protótipo do sistema PSF Manager, no âmbito da saúde pública. Tal projeto chamou bastante atenção pelo nível de detalhamento, recursos e diversidade de integração com dispositivos de hardware, tais como TV, impressora térmica, monitor e computador, além de representar uma solução para um problema real, conforme Figura 1. Os alunos responsáveis pelo protótipo cursaram a disciplina de IHC no $1^{\circ}$ semestre de 2019 e são coautores deste relato.

Nas aulas dedicadas à apresentação do projeto (formatos presencial e remoto), o protótipo interativo foi apresentado primeiramente, seguido dos slides contendo as telas

\footnotetext{
${ }^{2}$ Ferramenta gratuita para download e instalação nos sistemas operacionais: Windows, Linux e Mac OS. Fonte: https://pencil.evolus.vn/

${ }^{3}$ Ferramenta online com versão gratuita e acessível via navegador. Fonte: www.figma.com
} 


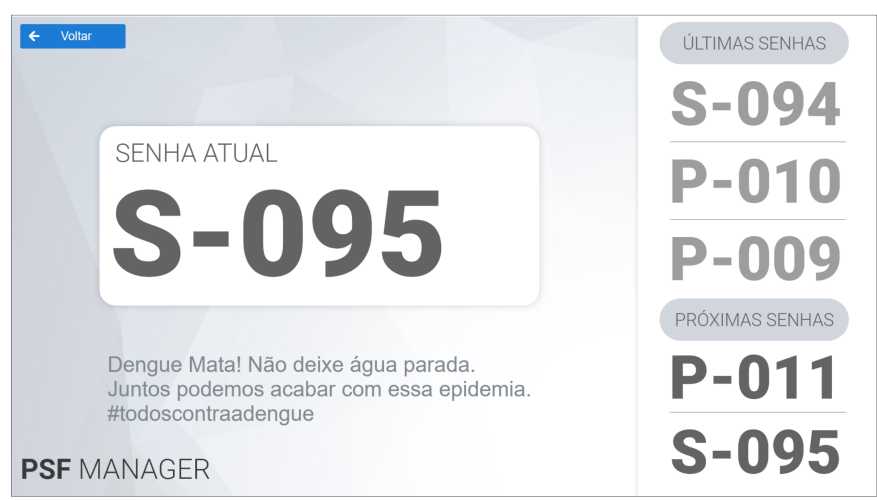

(a)

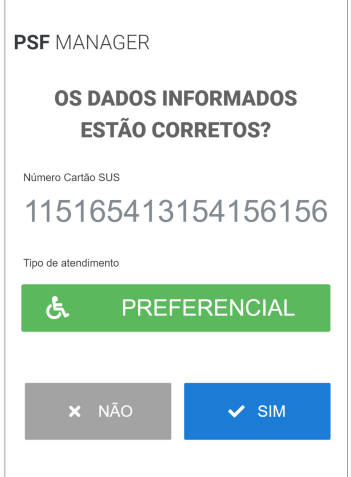

(b)

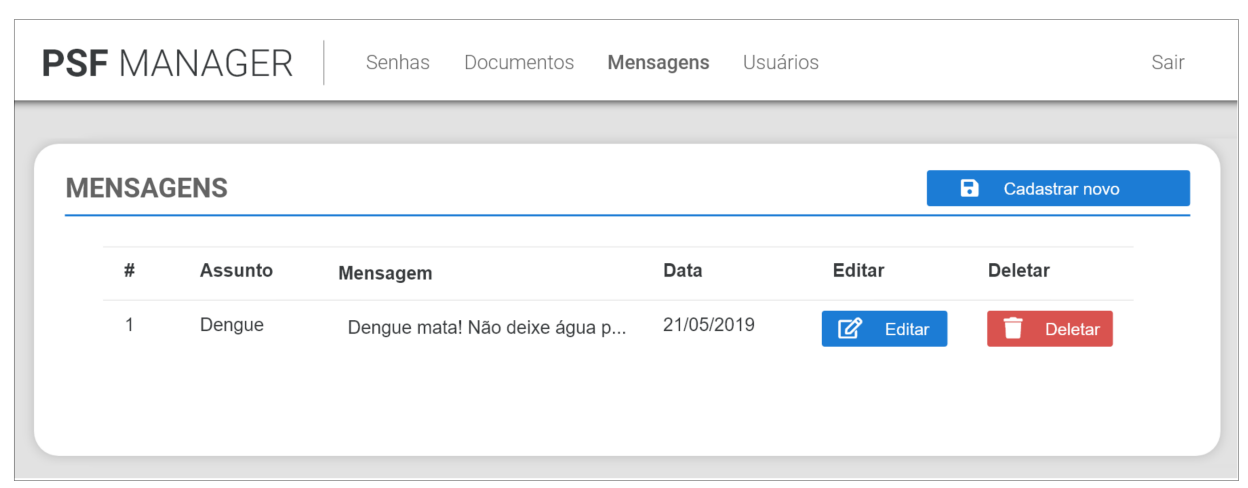

(c)

Figura 1. Protótipo do Sistema PSF Manager. (a) Terminal de atendimento. (b) Terminal de impressão de senha. (c) Tela de mensagens do sistema.

cujos elementos presentes remetessem às heurísticas escolhidas. A Figura 1 apresenta as telas correspondentes às seguintes heurísticas e justificativas do grupo sobre as mesmas:

(a) Conteúdo relevante e expressão adequada: a tela mostra as principais informações em destaque, sem poluição visual (a ser exibida no monitor de TV).

(b) Projeto para erros: o paciente deve verificar dados de sua senha antes de realizar a impressão (uma mensagem de alerta aparece no visor).

(c) Visibilidade do estado do sistema: a opção atual sempre fica destacada no menu superior, facilitando a identificação e navegação do usuário (no caso, o item "Mensagens").

Cada equipe, independente da modalidade, apresentou o projeto de forma muito similar ao que foi relatado anteriormente. Durante as apresentações, coube à professora intervir em duas situações: (i) quando a heurística apresentada não tinha relação com o que se via nas telas prototipadas; (ii) quando houvesse mais de uma heurística presente na tela apresentada. Na própria Figura 1 (a) e (b), também encontram-se presentes a heurística projeto estético e minimalista (com informações sucintas e bem apresentadas) e em (c), a heurística consistência e padronização (na formatação da fonte - tipologia e nas cores dos botões).

\section{Considerações finais}

Em ambas as abordagens (presencial e remoto) os alunos realizaram o projeto de acordo com o que se esperava: a aplicação das heurísticas no design dos protótipos das telas. 
Alguns resultados se destacaram, como o apresentado na Seção 4 e, pelo conhecimento da professora, a sua qualidade não foi influenciada pela modalidade de ensino, mas sim pela experiência prévia de um dos alunos da equipe que, na época, trabalhava com desenvolvimento de artes gráficas. A questão visual foi levada em consideração, mas não foi critério de avaliação, uma vez que não houve espaço suficiente para explorar técnicas de design de interfaces devido à carga horária da disciplina.

Considera-se que o objetivo principal do projeto interdisciplinar foi alcançado, conforme se observa pelos feedbacks dos alunos coautores deste relato. Um deles disse que "todo o projeto nos levou a vivência da prática, o que acontece no desenvolvimento de software, o que nos fez sentir preparados para o mercado". Outro aluno exprimiu sua opinião comparando a execução do projeto com sua vivência profissional: "seu desenvolvimento foi bem próximo do que vivencio em meu meio profissional como desenvolvedor”.

Além disso, o desenvolvimento de soft skills, conforme descrito na Seção 3, também foi percebido por um aluno coautor: "com o projeto, desenvolvemos diversas habilidades, começando pela criatividade e resolução de um problema real, além de liderança e trabalho em grupo".

Em ambas as abordagens, o engajamento dos alunos foi similar. Em relação à procura, em quase todas as aulas no formato presencial, os alunos buscaram sanar dúvidas quanto à ferramenta de design. Já no ensino remoto, esta busca ocorreu em menor quantidade. Acredita-se que o motivo seja por causa da gravação da aula explicativa sobre o Figma, a qual foi disponibilizada a todos e puderam assistir quantas vezes quisessem.

\section{Referências}

Barbosa, S. D. J. (2010). Interação humano-computador. Elsevier.

Benyon, D. (2011). Interação humano-computador. Pearson Prentice Hall, 2th edition.

Chagas, R. L. C. P. (2020). Aprendizagem baseada em projeto na prática. https: / / www . youtube.com/watch?v=ctX5VcJAllM. Palestra Online.

de Lima, I. F. G., de Melo, M. C., da Silva, W. E., and Falcão, T. P. (2019). Interdisciplinaridade e ihc: Possibilidades no contexto da licenciatura em computação. In Anais Estendidos do XVIII Simpósio Brasileiro sobre Fatores Humanos em Sistemas Computacionais, pages 82-87, Porto Alegre, RS, Brasil. SBC.

ISO 9241-11 (2018). Ergonomics of human-system interaction - Part 11: Usability: Definitions and concepts. Standard, International Organization for Standardization.

Krajcik, J. S. and Blumenfeld, P. C. (2005). Project-Based Learning, page 317-334. Cambridge Handbooks in Psychology. Cambridge University Press.

Mesquita, D., Chagas, R., Lima, R., and Chagas, J. (2018). Assessment models in two project based learning (pbl) approaches: an exploratory study.

Nielsen, J. (1993). Usability Engineering. Morgan Kaufmann Publishers Inc., San Francisco, CA, USA.

Sobral, W. S. (2019). Design de interfaces: introdução. Érica. 